\title{
AN INTERESTING CASE OF TRICHOBEZOAR
}

Rajshekhar Patili ${ }^{1}$, Vishal Kadeli ${ }^{2}$, Hareesh Belagali ${ }^{3}$

\section{HOW TO CITE THIS ARTICLE:}

Rajshekhar Patil, Vishal Kadeli, Hareesh Belagali. "An interesting case of Trichobezoar". Journal of Evolution of Medical and Dental Sciences 2014; Vol. 3, Issue 01, January 06; Page: 51-55.

ABSTRACT: Trichobezoar is a very rare condition that is usually diagnosed at a late stage due to etiology of the condition. It is usually seen in young females who invariably have a psychiatric disorder like trichotillomania, trichophagia or depression. Here we report a case of trichobezoar which presented in the surgical out-patient department of our hospital.

KEYWORDS: Trichobezoar, Depression, Trichophagia, Trichotillomania

INTRODUCTION: A bezoar is a mass of undigested material within the gastrointestinal tract. The term bezoar derives from the Arabic word Badzehr, which means antidote ${ }^{1}$. Bezoars were used as antidotes against plague, snake-bite, leprosy and epilepsy by physicians from 12th to 18th century ${ }^{2}$. Trichobezoar is from the Greek word trich which means hair ${ }^{3}$.Trichobezoar is often associated with trichotillomania (hair pulling) and trichophagia (hair swallowing). Trichotillomania may be unconsciously or unintentionally done and is part of the DSM IV psychiatric classification of impulse control disorders ${ }^{4}, 5$.Over a period of time, continuous ingestion of hair leads to the impaction of hair together with mucus and food, causing the formation of a trichobezoar. In most cases the trichobezoar is confined within the stomach. In some cases, however, the trichobezoar extends through the pylorus into jejunum, ileum or even colon. This condition, called Rapunzel syndrome, was first described by Vaughan et al. in 19686,7.Trichobezoars most commonly occur in adolescent females ${ }^{8}$. The site of hair pulling is most commonly from the scalp, but can occur from the eyelashes, eyebrows, and pubic area'.

CASE REPORT: A seventeen year old girl presented to the surgery Out-patient department with complaints of pain in abdomen and mass in the upper abdomen since 15 days. The pain was vague and continuous type. Patient was studying in a residential school and her mother had expired 5 years back and father was a chronic alcoholic. On general examination, she was moderately built but had pallor and short hair (figure 1).On enquiry she did not give any history of plucking or eating her hair. On local examination a mass was felt in the epigastric region (figure 2) which was non tender, firm and mobile. Ultrasound and CT revealed a large gastric mass measuring $22 \times 14 \mathrm{~cm}$.Upper gastrointestinal endoscopy revealed presence of huge mass of hair occupying the cardia and body of stomach. Considering the size of the bezoar endoscopic removal was not done and a conventional laparotomy and a gastrotomy (figure 3and 4) was done with careful removal of the entire bezoar (figure5 and 6).The patient was discharged on postoperative day ten and sent for psychiatric consultation. The psychiatrist diagnosed her as a case of depression and prescribed her SSRIs and a thorough counseling was done. Patient came back for follow-up after 3 weeks and is doing fine and is being reviewed by the psychiatrist every 3 months.

DISCUSSION: Trichobezoar is mainly seen in young adolescent females with underlying psychiatric or social problems. Depression, trichotillomania, trichophagia are the common underlying disorders, 
however, other mental disorders such as abuse, pica, obsessive compulsive disorder and anorexia nervosa may also be associated with it $10,11,12$. When not recognized, the trichobezoar continues to grow in size and weight due to the continued ingestion of hair. This increases the risk of severe complications, such as gastric mucosal erosion, ulceration and even perforation of the stomach or the small intestine. In addition, intussusception, obstructive jaundice, protein-losing enteropathy, pancreatitis and even death have been reported as complications of (unrecognized) trichobezoar in the literature $13,14,15,16,17$.Presentation ranges from nonspecific abdominal or epigastric pain, to a range of complications as mentioned.

Clinical examination often reveals a large mobile epigastric mass that may be indentable; the so-called Lamerton's sign ${ }^{18}$.Endoscopy is usually diagnostic. The hair appears black (despite the normal hair color) due to denaturing of the hair protein by the acid. The most common diagnostic tool used in the literature is a CT scan, with a typical image showing a well-defined intraluminal ovoid heterogeneous mass with interspersed gas ${ }^{19,20}$.

Management of this condition is either by endoscopic removal, laparoscopy or laparotomy to carry out a gastrotomy.Gorter et al., in a retrospective review of 108 cases of trichobezoar concluded that only $5 \%$ of endoscopic removal attempts were successful21.In a series of 15 patients with bezoars, a 15-year-old girl underwent fragmentation of a large trichobezoar by means of a modified needle-knife and monopolar coagulation current ${ }^{22}$. In most case reports, however, fragmentation was considered impossible because of size, density and hardness, and endoscopy was not considered a viable therapeutic option $23,24,25,26$, and 27 . Moreover, as the removal of all fragments requires manifold repeated introduction of the endoscope, pressure ulceration, esophagitis and even esophageal perforation may ensue ${ }^{28,29}$. Additionally, fragments of a large trichobezoar might migrate after fragmentation or repeated manipulation through the pylorus, causing intestinal obstruction further distally ${ }^{30}$.

Laparoscopy has a much higher success rate than endoscopy. Successful laparoscopic removal, however, requires significantly longer operation time as compared to conventional laparotomy, mostly due to the complexity of the operation. Careful examination of the entire digestive system (intestine and stomach) is necessary in order to prevent secondary intestinal obstruction due to satellites. With laparoscopy this procedure is far more challenging. The risk of spilling contaminated hair fragments into the abdominal cavity makes the laparoscopic approach even less attractive. In addition, due to the rarity of trichobezoars, the technique of laparoscopic removal and inspection of the entire intestine may be hard to acquire. The benefits of laparoscopic removal of trichobezoars with intestinal obstruction have been reported to have better cosmetic result, less postoperative complications and reduced admittance time ${ }^{31}$.

Laparotomy has so far had a $100 \%$ success rate. Due to $100 \%$ success rate, the relatively low complication rate, the low complexity, and the ability to carefully examine the entire gastrointestinal tract for satellites in a short period of time, laparotomy is still considered the treatment of choice.

CONCLUSION: Although trichobezoars are rare, a high index of suspicion in patients, especially young females with history suggestive of depression, other psychiatric disorders or those living in residential schools, with complaints of pain abdomen, loss of appetite, weight and hair can help in early diagnosis of this condition and can be treated either conservatively or through a lesser invasive procedure like endoscopy. Even though the advanced form of the condition can be successfully 
treated by laparotomy, identification of such vulnerable patients and prompt counseling of them and their care-takers can prevent the morbidity and financial burden.

\section{REFERENCES:}

1. A. Samad, M. Ahmadand Z. Latif."Bezoars: a review and report of two cases, " Journal of the College of Physicians and Surgeons Pakistan, vol. 7, no. 6, pp. 263-265, 1997.

2. S. Khattak and K. Asghar."Trichobezoar, " Gomal Journal of Medical Sciences, vol.2, no. 1, pp. 25-26, 2004.

3. M. E. Rabie, A. R. Arishi, A. Khan, H. Ageely, G. A. S. El-Nasrand M. Fagihi."Rapunzel syndrome: the unsuspected culprit, " World Journal of Gastroenterology, vol. 14, no. 7, pp. 1141-1143, 2008

4. American Psychiatric Association, Diagnostic and Statistical Manual of Mental Disorders.American Psychiatric Association, Washington, DC, USA, 4th edition, 2000.

5. G. A.Christenson and S. J. Crow."The characterization and treatment of Trichotillomania, "Journal of Clinical Psychiatry, vol. 57, no. 8, pp. 42-49, 1996

6. Vaughan ED. Jr., Sawyers JL, Scott HW.Jr. The Rapunzel syndrome. An unusual complication of intestinal bezoar. Surgery. 1968; 63:339-343.

7. Naik S, Gupta V, Rangole A, Chaudhary AK, Jain P, Sharma AK. Rapunzel syndrome reviewed and redefined. Dig Surg. 2007; 24:157-161.

8. M. R. Phillips, S. Zaheerand G. T. Drugas.“Gastric trichobezoar: case report and literature review, " Mayo Clinic Proceedings, vol. 73, no. 7, pp. 653-656, 1998

9. G. A. Christenson, T. B. Mackenzieand J. E. Mitchell."Characteristics of 60 adult chronic hair pullers, " American Journal of Psychiatry, vol. 148, no. 3, pp. 365-370, 1991

10. Bouwer C, Stein DJ. Trichobezoars in trichotillomania: case report and literature review. Psychosom Med. 1998; 73:653-656.

11. Armstrong JH, Holtzmuller KC, Barcia PJ. Gastric trichobezoar as a manifestation of child abuse.Curr Surg. 2001;58:202-204

12. Cohen LJ, Stein DJ, Simeon D, Spadaccini E, Rosen J, Aronowitz B, et al. Clinical profile, comorbidity and treatment history in 123 hair pullers: a survey study. J ClinPsychiatr. 1995; 56:319-326.

13. Ventura DE, Herbella FAM, Schettini ST, Delmonte C. Rapunzel syndrome with a fatal outcome in a neglected child. J Pediatr Surg. 2005; 40:1665-1667.

14. Mehta $\mathrm{MH}$, Patel RV. Intussusception and intestinal perforations caused by multiple trichobezoars. J Pediatr Surg. 1992; 27:1234-1235.

15. Schreiber H, Filston HC. Obstructive jaundice due to gastric trichobezoar. J Pediatr Surg. 1976; 11:103-104.

16. Hossenbocus A, Colin-Jones DG. Trichobezoar, gastric polyposis, protein losing enteropathy and steatorrhoea.Gut. 1973; 14:130-132.

17. Shawis RN, Doig CM. Gastric trichobezoar with transient pancreatitis. Arch Dis Child. 1984; 59:994-995.

18. A. J. Lamerton."Trichobezoar: two case reports-a new physical sign," American Journal of Gastroenterology, vol. 79, no. 5, pp. 354-356, 1984. 
19. J.Tamminen and D. Rosenfeld.“CT diagnosis of a gastric trichobezoar,” Computerized Medical Imaging and Graphics, vol. 12, no. 6, pp. 339-341, 1988.

20. F. Navab and J. Sabol.“Images in clinical medicine, ” New England Journal of Medicine, vol. 336, no. 24, p. 1721, 1997.

21. R. R. Gorter, C. M. F. Kneepkens, E. C. J. L. Mattens, D. C. Aronson, and H. A. Heij.“Management of trichobezoar: case report and literature review, " Pediatric Surgery International, vol. 26, no. 5, pp. 457-463, 2010

22. Wang YG, Seitz U, Li ZL, Soehendra N, Qiao XA. Endoscopic management of huge bezoars. Endoscopy. 1998; 30:371-374.

23. Palanivelu C, Rangarajan M, Senthilkumar R, Madankumar MV. Trichobezoars in the stomach and ileum and their laparoscopy-assisted removal: a bizarre case. Singapore Med J. 2007;48:37-39

24. Alsafwah S, Alzein M. Small bowel obstruction due to trichobezoar: role of upper endoscopy in diagnosis. GastrointestEndosc. 2000; 52:784-786.

25. Backer A, Nooten V, Vandenplas Y. Huge gastric trichobezoar in a 10 year old girl: case report with emphasis on endoscopy in diagnosis and therapy. J PediatrGastroenterolNutr. 1999; 28:513-515.

26. Gossum A, Delhaye M, Cremer M. Failure of non-surgical procedures to treat gastric trichobezoar. Endoscopy. 1989; 21:113.

27. Soehendra N. Endoscopic removal of a trichobezoar. Endoscopy. 1989; 211:201.

28. Kanetaka K, Azuma T, Ito S, Matsuo S, Yamaguchi S, Shirono K, et al. Two-channel method for retrieval of gastric trichobezoar: report of a case. J Pediatr Surg.2003;38

29. Dumonceaux A, Michaud L, Bonnevalle M, Debeugny P, Gottrrand F, Turck D. Trichobezoars in children and adolescents. Arch Pediatr. 1998;5:996-99

30. Diettrich NA, Gau FC. Postgastrectomyphytobezoar-endoscopic diagnosis and treatment. Arch Surg. 1985;120:432-435

31. Yau KK, Siu WT, Law BK, Cheung HY, Ha JP, Li MK. Laparoscopic approach compared with conventional open approach for bezoar induced small bowel obstruction. Arch Surg. 2005; 140:972-975.

\section{CLINICAL PHOTOGRAPHS:}

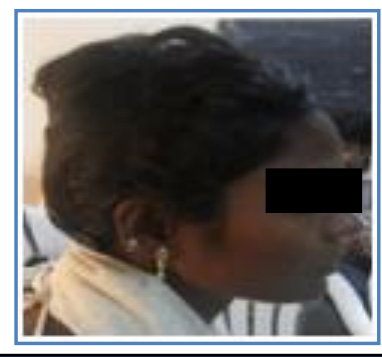

Fig. 1: Female patient with unusually short hair

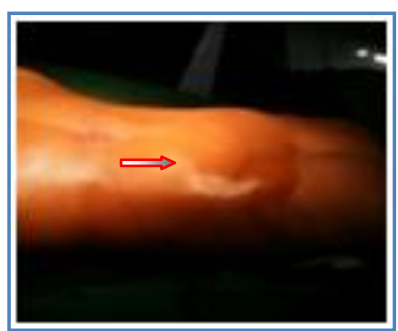

Fig. 2: Mass in the epigastric region 


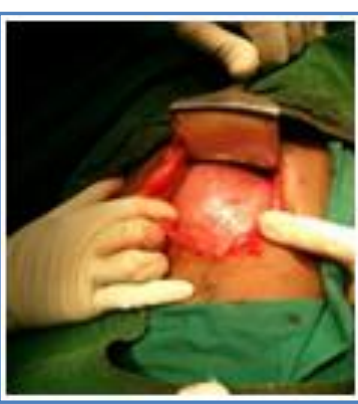

Fig. 3: Laparotomy showing distended stomach

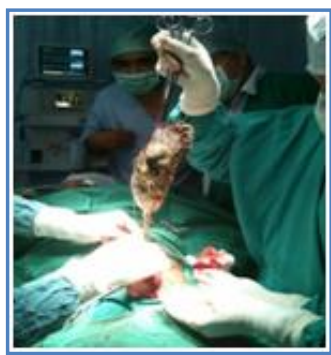

\section{Fig. 5: The entire trichobezoar} being delivered out

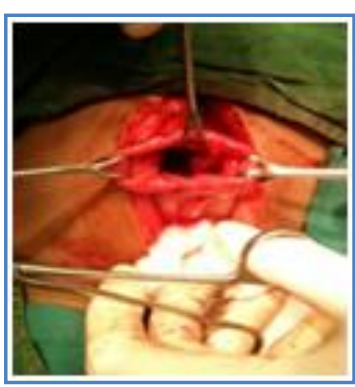

Fig. 4: Gastrotomy with visible tuft of hair inside stomach

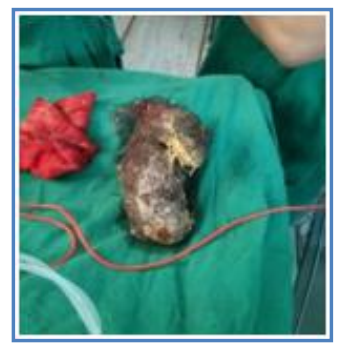

Fig. 6: The specimen after complete removal

\section{AUTHORS:}

1. RajshekharPatil

2. Vishal Kadeli

3. HareeshBelagali

\section{PARTICULARS OF CONTRIBUTORS:}

1. Associate Professor, Department of General Surgery, Basweshwar Teaching and General Hospital, Gulbarga.

2. $3^{\text {rd }}$ Year Resident, Department of General Surgery, Basweshwar Teaching and General Hospital, Gulbarga.

3. $2^{\text {nd }}$ Year Resident, Department of General Surgery, Basweshwar Teaching and General Hospital, Gulbarga.

\section{NAME ADDRESS EMAIL ID OF THE CORRESPONDING AUTHOR:}

Dr. Rajshekhar Patil,

Block No. 56, Swastik Nagar,

Bilgundi Layout, Sedam Road,

Gulbarga - 585105.

Email-drrjsp@gmail.com

Date of Submission: 12/12/2013.

Date of Peer Review: 13/12/2013.

Date of Acceptance: 20/12/2013.

Date of Publishing: 01/01/2014 